Int. J. Dev. Biol. 52: 647-656 (2008)

doi: $10.1387 / \mathrm{ijdb} .072512 \mathrm{as}$

\title{
Genes required for the common miracle of fertilization in Caenorhabditis elegans
}

\author{
ANDREW SINGSON*, JULIE S. HANG and JEAN M. PARRY \\ Waksman Institute and Department of Genetics, Rutgers University, Piscataway, New Jersey, USA
}

\begin{abstract}
Fertilization involves multiple layers of sperm-egg interactions that lead to gamete fusion and egg activation. There must be specific molecules required for these interactions. The challenge is to determine the identity of the genes encoding these molecules and how their protein products function. The nematode worm Caenorhabditis elegans has emerged as an efficient model system for gene discovery and understanding the molecular mechanisms of fertilization. The primary advantage of the $C$. elegans system is the ability to isolate and maintain mutants that affect sperm or eggs and no other cells. In this review we describe progress and challenges in the analysis of genes required for gamete interactions and egg activation in the worm.
\end{abstract}

KEY WORDS: C. elegans, fertilization, egg activation

It has been said that birth is the "common miracle". We would argue that there is deeper meaning to this statement. Successful reproduction requires so many precise steps that there are innumerable places where things can go wrong and lead to infertility. Gametes have to be produced and mature at the right time. They must be released or delivered to the right place via specific mating behaviors of the organism. Sperm and eggs need to function properly in order to get together and complete fertilization. Finally the zygote must effectively transition into a developing embryo. Environmental and genetic factors can interfere with any of these events and lead to infertility. The more that one learns about the process, the more it seems like a miracle that any organism can reproduce efficiently. This of course makes understanding fertilization a very compelling area of study. It is a distinct honor to contribute a review in a volume dedicated to the memory of Dr. David Garbers. As evidenced by his contributions to the field, Dr. Garbers was devoted to understanding the common miracle of fertilization.

\section{Introduction}

The major events of fertilization and egg activation have been well described for many species and there has been exciting progress in identifying the molecules that mediate the many steps of fertilization (see other reviews in this issue). However, a full understanding of gamete interactions at the molecular level in any species will require the identification of all of the key cellular components in both sperm and eggs. With this goal in mind, one of the primary advantages to genetic analysis is that it permits the unbiased recovery of functionally important molecules regardless of abundance or biochemical properties (Geldziler et al., 2004). Forward and reverse genetic approaches to study reproduction have been reported recently for flies (Wakimoto et al., 2004) and mice (Lessard et al., 2004; Roy and Matzuk, 2006). Although these approaches have identified many interesting mutants that alter key processes such as meiosis and gametogenesis, molecules specifically required for gamete interactions have yet to be reported. The study of $C$. elegans mutants offer an exceptional opportunity to efficiently define and study gamete components required for sperm-egg interactions at fertilization (Greenstein, 2005; Jorgensen and Mango, 2002; Singson, 2001; Yamamoto et al., 2006). Many mutants have been identified that specifically affect sperm-egg interactions or egg activation (see Table 1) (Browning and Strome, 1996; Chatterjee et al., 2005; Kadandale etal., 2005; Maruyama et al., 2007; Singson, 2001; Singson et al., 1998; Xu and Sternberg, 2003). Genetic analysis in C. elegans is complemented by the advanced genomics, proteomics and other molecular tools available for the worm (Gunsalus et al., 2005; Lamitina, 2006; Li et al., 2004; Maruyama and Singson, 2006;

Abbreviations used in this paper: DC-STAMP; dendritic cell-specific transmembrane protein; EGF, epidermal growth factor; LDL, low density lipoprotein; PTPL, protein tyrosine phosphatase-like; TRPC, transient receptor potential-canonical.

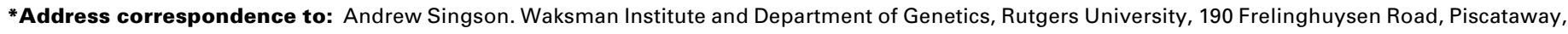
NJ 08854, USA. Fax: +1-732-445-5735. e-mail: singson@waksman.rutgers.edu 

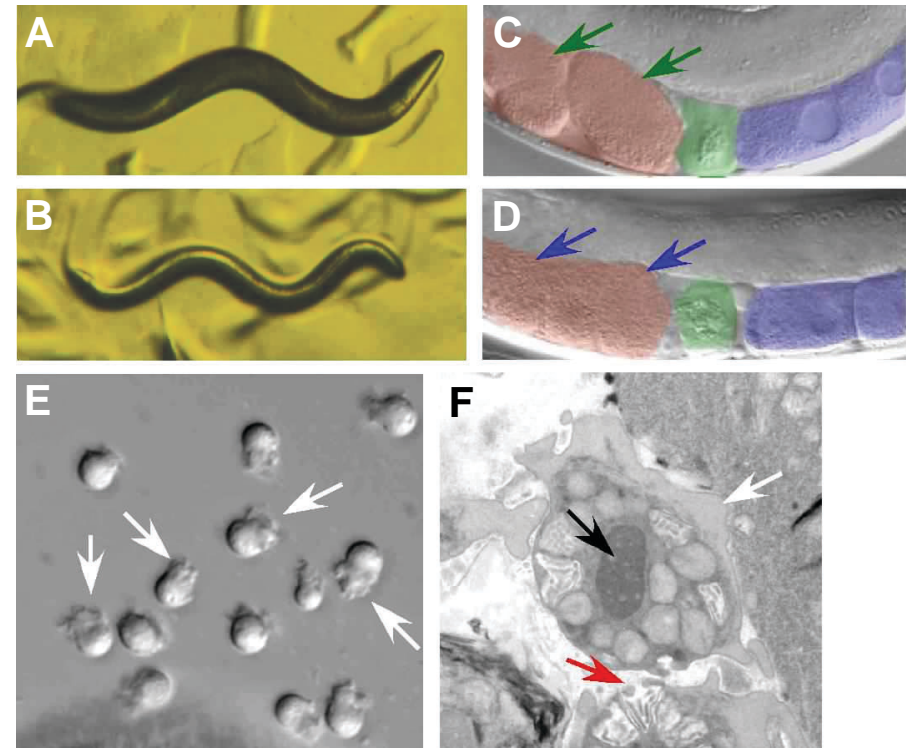

Fig. 1. The $C$. elegans sexes, reproductive tract and gametes. (A) $A$ hermaphrodite. (B) A male. (C) A wild-type hermaphrodite reproductive tract in the region of the spermatheca with developing embryos in the uterus. A one-cell embryo and a dividing embryo can be seen in the uterus of this animal (green arrows). (D) A sterile mutant with unfertilized oocytes in the uterus (blue arrows). These cells do not divide or secrete an eggshell. (C-D) The blue tinted region indicates the oviduct, the green tinted region indicates the spermatheca and the pink tinted region indicates the uterus. (E) A Nomarski DIC micrograph of wild-type amoeboid sperm. White arrows point to examples of pseudopods. (F) A transmission electron micrograph of a wild-type sperm in the hermaphrodite spermatheca. The white arrow points to the pseudopod. This plane of section also shows a fused membranous organelle in an adjacent sperm (red arrow).

Miller, 2006; Piano et al., 2006). Finally, C. elegans are transparent allowing direct observation of gametes and reproductive events (Fig. 1) (L'Hernault, 2006).

\section{General features of $C$. elegans reproductive biology}

C. elegans can exist as hermaphrodites (Fig. 1A) or males (Fig. 1B). Hermaphrodite worms produce both sperm and oocytes, albeit at different time points, allowing for self-fertilization (Ward and Carrel, 1979). Male worms only produce sperm, and are able to produce outcross progeny when mated to hermaphrodites. Oocytes mature and are ovulated about every 20 minutes from the oviduct (McCarter et al., 1999) (Fig. 1C). Fertilization occurs in the hermaphrodite when oocytes enter the spermatheca and come in contact with sperm (Samuel et al., 2001; Ward and Carrel, 1979). Although oocytes will contact many sperm simultaneously in the spermatheca, only a single sperm enters each oocyte. The block to polyspermy and its exact relationship to egg activation is not known.

The union of sperm and egg at fertilization triggers egg activation and converts the egg into a developing embryo. The triggers and specific events of egg activation vary from species to species (Ducibella et al., 2006; Jones, 2005; Stitzel and Seydoux, 2007; Tsaadon et al., 2006). In C. elegans, egg activation includes an increase of intracellular calcium, the proper completion of meiosis and polar body formation, the reorganization of the cortical actin cytoskeleton, and dynamic remodeling of the oocyte surface with secretion of a chitin eggshell (Maruyama et al., 2007; Samuel et al., 2001; Singson, 2001; Stitzel and Seydoux, 2007). These events are completed as the egg moves through the spermatheca and uterus.

Eggs are laid prior to the completion of embryogenesis and the hatching of juvenile worms. If a worm is infertile due to mutations that affect gamete function at fertilization (see below), the uterus fills with unfertilized oocytes (Fig 1D). These unfertilized and dying oocytes become endomitotic and are also laid by hermaphrodites (Ward and Carrel, 1979).

\section{The amoeboid sperm and thinly coated oocytes of $C$. elegans}

There are several differences between nematode and mammalian gametes. $C$. elegans sperm are amoeboid and lack flagella and acrosomes familiar to mammalian sperm (Fig. 1E, F). Oocytes do not have a thick egg coat but do have a recently defined thin vitelline layer and a cortical granule reaction (Bembenek et al., 2007). Despite these differences, both nematode and mammalian gametes have to accomplish the same fundamental tasks: the sperm must be able to acquire motility, locate and move toward an oocyte, bind to/fuse with the oocyte and provide paternal contributions to the zygote; the oocyte must be able to undergo egg activation once fertilization has occurred and provide most of the raw material to support embryogenesis.

C. elegans sperm seem to be well adapted to the crowded environment of the worm reproductive tract and display complex cellular behaviors (Bottino et al., 2002; Kubagawa et al., 2006; Theriot, 1996). After undergoing spermiogenesis or sperm activation and gaining motility (Shakes and Ward, 1989b; Singson, 2006; Ward etal., 1983), sperm must crawl towards the spermatheca and maintain their position in the reproductive tract against a continual flow of eggs. Sperm migratory behavior and recruitment to oocytes is regulated by a prostaglandin-like signal(s) (Kubagawa et al., 2006). Polyunsaturated fatty acid precursors of this signal are transported from the intestine to the yolk of developing oocytes. The full nature of the signal-generating pathway, its release by oocytes, and detection by sperm remains to be elucidated. In some fertilization defective mutants, sperm may be confused by the presence of unfertilized oocytes in the uterus. In these mutants, sperm are lost rapidly and get swept out of the reproductive tract (Kadandale et al., 2005; L'Hernault et al., 1988). However, the underlying mechanism of sperm loss in these mutants is unknown.

\section{Sterile mutants}

A list of known gamete function and egg activation genes are listed in Table 1 and their predicted protein products are shown schematically in Figure 2. All of these genes are defined by loss of function mutations that lead to sterility. The sterile phenotypes and mutations associated with these genes are generated in various ways. The most common approach is random mutagenesis and the selection of animals with fertility defects (Anderson, 1995; Jorgensen and Mango, 2002; L'Hernault et al., 1988; Ward et al., 1981). Based on allele frequency, many more sterile 
mutants should be isolated (L'Hernault, 2006; L'Hernault et al., 1988). Once identified, sterility-causing mutations are maintained by genetic manipulations available in the worm. These genetic manipulations include various crossing, fertile sibling selection or balancer chromosome schemes (Edgley et al., 1995; Hodgkin, 1999; Singson, 2001).

Reverse genetics and gene knockout have been another fruitful approach that has identified important fertilization molecules (Geldziler et al., 2004). C. eleganswas the first multicellular organism to have a completely sequenced genome (Hodgkin et al., 1995). C. elegans biologists are avid consumers of genomic data and our lab has used this approach to investigate the role of molecules that are specifically expressed in sperm or oocytes (Geldziler et al., 2006; Geldziler et al., 2005; Kadandale etal., 2005; Reinke et al., 2000). Once a gene of interest has been identified, its function can be tested by isolating a knockout of the gene or using double strand RNA interference (RNAi, see below) (Fire, 1999; Fire et al., 1998). Gene knockouts can be requested from the various $C$. elegans knockout consortiums or generated following standard protocols (Barstead, 1999).

Additional fertility phenotypes can be generated by RNAi (Kadandale et al., 2005; Maeda et al., 2001; Maruyama et al., 2007). However RNAi has important limitations to consider. RNAi "knockdown" is only a phenocopy of loss of function mutations and are not transmitted following the rules of Mendelian inheritance. Phenotypes generated by RNAi may not always represent a full loss of function. Therefore, it is important to follow up RNAi experiments with the analysis of "real" mutations generated by random mutagenesis or gene knockout. Furthermore, many genes are refractory to RNAi. Sperm genes are particularly insensitive to RNAi (Singson, 2001).

It is important to note that there are a large number of "sterile" mutants that have been isolated in $C$. elegans. For instance, there are many mutations that cause defects in gametogenesis or germline development and proliferation (Hubbard and Greenstein, 2000; Hubbard and Greenstein, 2005; L'Hernault, 2006). Male fertility can be confounded by an inability to mate with hermaphrodites (Hodgkin, 1983). There are scores of mutations that cause embryonic lethality (Schnabel and Priess, 1997). Since these mutant animals produce no viable progeny, they are often labeled as sterile.

The specific fertility mutants that we will discuss in the remainder of this review will be divided into two main classes. These two classes are "sperm function" and "egg function" mutant genes. The $C$. elegans community is ruled by strict gene nomenclature guidelines (Hodgkin, 1997). Sperm-sterile mutants are referred to as spe for spermatogenesis defective or fer for fertilization defective while egg sterile mutants are referred to as egg for eggsterile. Specifically, spe and fer mutants are the mammalian equivalent of paternal infertility. Therefore spe and fer mutant hermaphrodites and males produce sperm that are incapable of fertilizing and/or activating wild-type oocytes. However, spe and fermutant hermaphrodites can produce progeny when crossed to wild-type males as a source of functional sperm. On the other hand, egg mutants suffer from the worm equivalent of maternal infertility. These mutants produce oocytes that cannot be fertilized and/or be activated by wild-type sperm. When egg hermaphrodites are crossed to wild-type males no progeny are produced. Furthermore, male worms carrying egg sterile mutants produce functional sperm and are fertile. Therefore, all new sperm-sterile and egg-sterile mutants can be easily distinguished by crossing wild-type males to mutant hermaphrodites and determining if progeny are produced.

\section{Sperm function molecules}

\section{spe-9 encodes an EGF repeat transmembrane molecule}

The spe- 9 mutant phenotype is considered the prototypical phenotype for sperm function mutations, because it was the first such gene identified (L'Hernault etal., 1988; Singson etal., 1998), and subsequent genes with similar characteristics are said to belong to the spe- 9 class (Singson, 2001). The first spe- 9 mutants were originally selected as hermaphrodites that could not produce self-progeny but were able to produce outcross-progeny when mated to wild-type males (L'Hernault et al., 1988). Male spe- 9 mutants are also sterile. Both hermaphrodite and male spe9 mutant animals produce sperm that are morphologically indistinguishable from wild-type sperm. Furthermore, spe-9 mutant sperm are fully motile, have no problem crawling to the spermatheca and contacting oocytes. Although these sperm reach the proper location for fertilization and contact oocytes, they cannot enter the oocytes. Taken together, these data indicate that spe9 mutants do not have a defect in spermatogenesis or general

\section{OOCYTE}

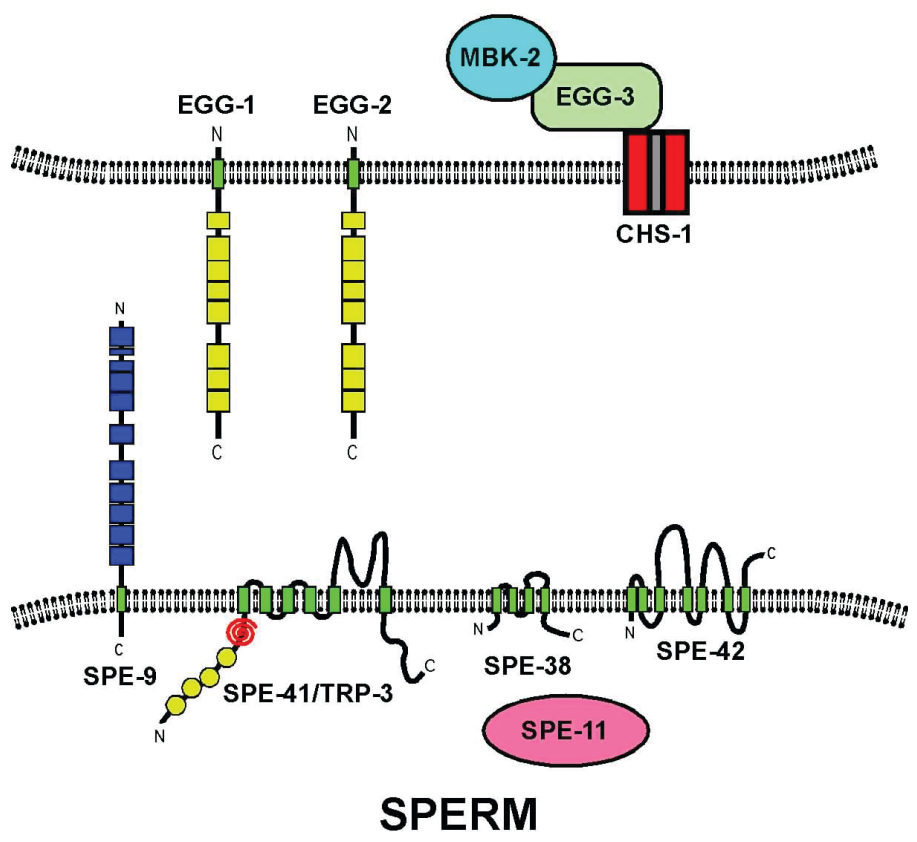

Fig. 2. A schematic of known gamete interaction and egg activation molecules. Descriptions of all molecules can be found in the text. Dark green rectangles indicate transmembrane domains in various membrane embedded molecules. Dark blue boxes indicate EGF repeats in SPE-9. Yellow boxes indicate LDL-receptor repeats in EGG-1 and EGG-2. Yellow circles indicate ankyrin repeats in SPE-41/TRP-3. The red coil indicates a coiled-coil domain in SPE-41/TRP-3. Where included, $N$ indicates the location $\mathrm{N}$-terminus and $\mathrm{C}$ indicates the $\mathrm{C}$-terminus of the various molecules. 
sperm behavior but rather have a defect in sperm function required specifically for fertilization.

The SPE-9 protein is a single-pass transmembrane molecule with a relatively short cytoplasmic tail and an extracellular domain that contains 10 epidermal growth factor (EGF)-like repeats (Fig. 2, Table 1) (Singson et al., 1998). Molecules that feature EGF-like motifs are involved in extracellular functions such as adhesive or ligand receptor interactions (Davis, 1990). Sequence analysis suggested that SPE-9 is most closely related to ligands of the Notch/LIN-12/GLP-1 family of transmembrane receptors (Singson et al., 1998). Immunofluorescence experiments confirmed the predicted topology of SPE-9 (Zannoni et al., 2003). Further, these experiments showed that SPE-9 displayed a dynamic localization pattern during spermiogenesis (post meiotic sperm differentiation) (Fig. 3). In round, non-motile spermatids, SPE-9 localized to the plasma membrane. In mature sperm, SPE-9 localized to the pseudopod. The localization of SPE-9 to the pseudopod of mature sperm suggests that like sperm from other nematodes, the pseudopod not only provides motility but is a key cellular region for penetrating the egg coat and interacting with the oocyte plasma membrane (Foor, 1968; Zannoni et al., 2003). The molecular nature of SPE- 9 and its localization to the sperm surface support the hypothesis that SPE-9 functions as a sperm ligand for an oocyte receptor (Fig. 4).

Various regions of the SPE-9 protein have been shown to be critical for function and may influence the specificity of molecular interactions with other molecules (Putiri et al., 2004; Singson et al., 1998). Sequencing of mutant alleles found that the extracel-

A Wild-type
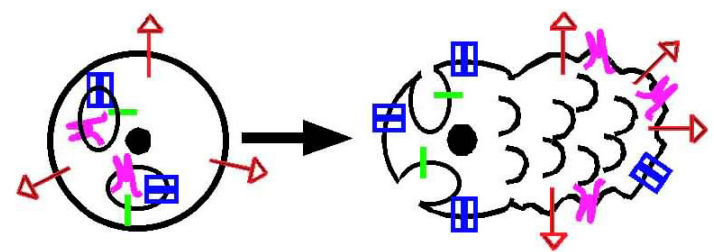

B

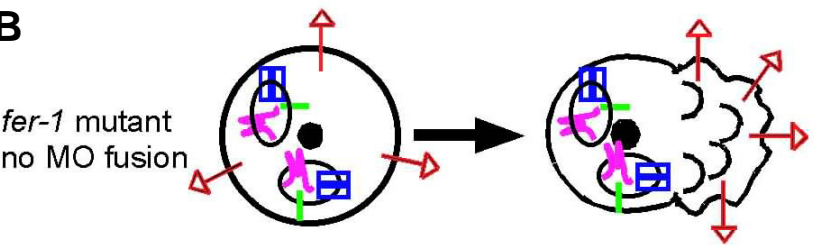

$$
\begin{aligned}
& \text { A SPE-9 sperm ligand } \\
& \text { y SPE-38 four pass membrane protein } \\
& \text { DI TRP-3/SPE-41 TRPC channel } \\
& \text { ICB4 MO marker }
\end{aligned}
$$

Fig. 3. Schematic diagram of protein localization in round spermatids and mature spermatozoa. Symbols for various molecules are indicated in the key. All sperm membrane molecules discussed in this review localize to the plasma membrane or membranous organelles (MOs). During post meiotic sperm differentiation (also known as spermiogenesis or sperm activation in C. elegans) indicated by the large arrows, MOs fuse with the plasma membrane and a pseudopod forms. During this time many molecules are redistributed. lular domain and EGF repeats of SPE-9 are critical for function. The EGF motifs in the extracellular domain of SPE-9 are also the most highly conserved regions with respect to homologues in other nematode species (Geldziler et al., 2006). Transgenic animals carrying differentially mutated versions of spe- 9 had fertility phenotypes that ranged from wild-type to complete sterility. Removal of repeats $2-6,6-10$, or $2-10$ results in a completely inactive protein. Individual point mutations in all 10 EGF motifs uncovered a differential sensitivity of these sequences to alteration. Some EGF repeats cannot tolerate mutation leading to a complete lack of fertility in transgenic animals. Other EGF sequences can be mutated to create animals with temperature sensitive (ts) fertility phenotypes. All ts mutations were generated by changing either conserved cysteine or glycine residues in the EGF motifs. Because EGF motifs are found in many proteins in different species, similar experimental strategies could be used to generate useful ts mutations in other EGF motif-containing molecules. SPE- 9 constructs lacking the transmembrane domain are non-functional, suggesting that SPE- 9 needs to be present on the sperm surface for function. Unlike its extracellular and transmembrane counterparts, the cytoplasmic tail of SPE- 9 is not required for its function, suggesting that SPE- 9 does not itself regulate sperm physiology or behavior. Additionally, since very little SPE9 is required for full fertility, it is more likely to function as a signaling molecule as opposed to an adhesion molecule (Putiri et al., 2004). Recent preliminary biochemical analysis indicates that the extracellular domain of SPE-9 can form dimers in solution and can bind to oocytes (B. Kong, A. Xu and A. Singson, unpublished). An important challenge will be to identify the oocyte receptor for SPE-9 (Fig. 4, see below).

\section{spe-38 encodes a novel four-pass integral membrane mol- ecule}

The spe-38gene is a member of the spe-9class and therefore displays the same mutant fertility phenotypes as described above. For example, spe-38 mutant sperm are incapable of fertilizing wild-type oocytes regardless of whether they are hermaphroditeor male-derived (Chatterjee et al., 2005). spe-38 sperm are indistinguishable from wild-type sperm with regards to morphology, motility and migratory behavior. The spe-38 gene is predicted to encode a novel four-pass integral membrane protein (Fig. 2). Structurally similar four-pass molecules have been implicated in processes such as gamete adhesion/fusion in mammals, membrane adhesion/fusion during yeast mating and the formation/function of tight-junctions in metazoa (Chatterjee et al., 2005). The biochemical activity of SPE-38 and many other structurally related molecules is unknown. Studies on SPE-38 could ultimately provide information about the biochemical activity of many of these structurally related molecules.

Immunofluorescence experiments revealed that SPE-38 has a dynamic distribution pattern that partially overlaps with that of SPE-9 (Fig. 3) (Chatterjee et al., 2005). In spermatids, SPE-38 is found in unique sperm vesicles called the membranous organelles (MOs). During spermiogenesis, the MOs fuse with the plasma membrane and form a permanent fusion pore in mature sperm (Fig. 1F) (Roberts et al., 1986; Shakes and Ward, 1989a; Ward et al., 1983). Glycoproteins, SPE-38 and SPE-41/TRP-3 (Fig. 3, see below) are released to the cell surface upon $\mathrm{MO}$ fusion with the plasma membrane. Once on the cell surface, SPE-38 
TABLE 1

\section{GAMETE FUNCTION AND EGG ACTIVATION GENES}

\begin{tabular}{|c|c|c|c|}
\hline Gene & Protein & Gamete localization & Primary references \\
\hline spe-9 & Transmembrane with EGF repeats & $\begin{array}{l}\text { Spermatid: plasma membrane. } \\
\text { Spermatozoon: pseudopod. }\end{array}$ & $\begin{array}{l}\text { Singson et al., } 1998 \\
\text { Zannoni et al., } 2003 \\
\text { Putiri et al., } 2004\end{array}$ \\
\hline spe-11 & Novel & Sperm cytoplasm around nucleus. & Browning and Strome, 1996 \\
\hline spe-13 & Not cloned & Unknown & \\
\hline spe-36 & Not cloned & Unknown & \\
\hline spe-38 & Novel four pass transmembrane protein & $\begin{array}{l}\text { Spermatid: membranous organelles. } \\
\text { Spermatozoon: pseudopod. }\end{array}$ & Chatterjee et al., 2005 \\
\hline spe-41/trp-3 & TRPC calcium channel & $\begin{array}{l}\text { Spermatid: membranous organelles. } \\
\text { Spermatozoon: plasma membrane. }\end{array}$ & Xu and Sternberg, 2003 \\
\hline spe-42 & Seven pass transmembrane with DC Stamp domains & $\begin{array}{l}\text { Unknown } \\
\text { Predicted membrane protein. }\end{array}$ & Kroft et al., 2005 \\
\hline fer-14 & Novel membrane protein & Unknown & $\begin{array}{l}\text { T. Kroft and } \\
\text { S. L'Hernault, unpublished }\end{array}$ \\
\hline $\begin{array}{l}\text { egg-1 } \\
\text { egg-2 }\end{array}$ & Transmembrane with LDL receptor repeats & Oocyte plasma membrane. & Kandandale et al., 2005 \\
\hline egg-3 & Protein tyrosine phosphatase-like family protein & Plasma membrane associated / oocyte cortex. & $\begin{array}{l}\text { Maruyama et al., } 2007 \\
\text { Stitzel et al., } 2007\end{array}$ \\
\hline
\end{tabular}

becomes restricted to the pseudopod in a distribution that is identical to SPE-9. Blocking MO fusion blocks SPE-38 translocation to the cell surface and the pseudopod. These results demonstrate that in addition to the sperm cell surface being morphologically and molecularly mosaic, there are multiple paths for proteins to reach the sperm cell surface and the pseudopod. Determining if SPE-38 has a biochemical function in MOs and/or the pseudopod during gamete interactions is an important future challenge. Live cell staining partially confirms the topology prediction for SPE-38 and demonstrates that at least part of the protein is extracellular in mature sperm. This extracellular loop could potentially interact with oocyte surface molecules during fertilization.

\section{spe-41/trp-3 encodes a TRPC calcium channel}

spe-41/trp-3 shares the same general fertility phenotypes common to other spe-9 class mutants (Xu and Sternberg, 2003). However, there is an important difference with regards to the requirement for this gene. Unlike all of the other spe- 9 class mutants, null alleles of spe-41/trp-3 are not completely sterile. Unmated mutant hermaphrodites are capable of producing very small broods of about $5 \%$ of the size of wild-type broods. Therefore, SPE-41/TRP-3 is not absolutely essential for fertilization. It is possible that this residual level of fertility depends on the activity of some other partially redundant channel protein in sperm.

SPE-41/TRP-3 is a member of the transient receptor potentialcanonical (TRPC) family of channel proteins (Fig. 2) (Xu and Sternberg, 2003). The loss of TRP-3 in C. elegans is correlated with a defect in calcium influx in activated sperm. Calcium influx in mammalian sperm is associated with the regulation of membrane fusion events (Jungnickel et al., 2001; Jungnickel et al., 2003). This defect in worm sperm calcium influx suggests that spe-41/trp-3 may be involved in mediating sperm-oocyte fusion. TRP channels are also known to play a role in regulating sperm motility (Castellano et al., 2003). However, spe-41/trp-3 mutant sperm do not have any detectable defects in motility or migratory behavior (Xu and Sternberg, 2003).

The subcellular localization of SPE-41/TRP-3 has been determined and it displays yet another unique and dynamic localization pattern (Fig. 3) (Xu and Sternberg, 2003). Like SPE-38, SPE-41/ TRP-3 is located in spermatid MOs. Its movement to the sperm surface is also dependent on MO fusion and this may be important for the regulation of channel activity. However, unlike SPE-9 and SPE-38, SPE-41/TRP-3 does not accumulate in any particular region of the plasma membrane of mature sperm.

\section{spe-42 encodes a DC-STAMP domain seven-pass integral membrane molecule}

Mutations in the spe-42 gene display a classic spe-9 class mutant phenotype (Kroft et al., 2005). The lack of functional SPE42 does not affect the localization of SPE-9, SPE-41/TRP-3 and

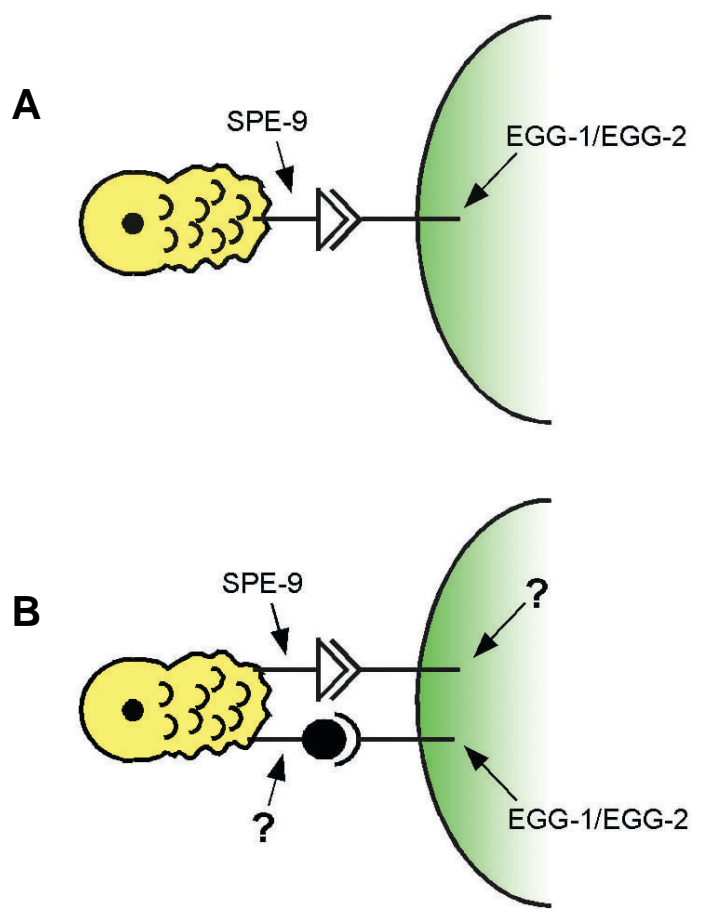

Fig. 4. Two possible models for the interactions of SPE-9 and EGG1/EGG-2. (A) SPE-9 and EGG-1/EGG-2 form a ligand receptor pair required for fertilization. (B) SPE-9 interacts with an unidentified oocyte surface receptor and the EGG-1 and EGG-2 oocyte surface receptors interact with an unidentified sperm surface ligand. 
SPE-38. Therefore SPE-42 does not regulate the expression or trafficking of these other spe-9class proteins. spe-42 is predicted to encode a 7-pass transmembrane protein that is solely expressed in sperm (Fig. 2). There are clear homologs of SPE-42 in many species of metazoa including in humans. Clues to the biochemical function of SPE-42 came from sequence analysis of the predicted protein. SPE-42 contains a dendritic cell-specific transmembrane protein (DC-STAMP) motif (Hartgers et al., 2000). The mammalian DC-STAMP protein is required for osteoclast precursor cell fusion (Kukita et al., 2004). It is striking that another DC-STAMP domain protein Sneaky is an acrosomal membrane protein that is required for plasma membrane breakdown during Drosophila fertilization (Wilson et al., 2006). It is an intriguing possibility that SPE-42 is in some way mediating $C$. elegans sperm-egg fusion. Localization data as well as experiments designed to determine the biochemical activity of SPE-42 should help address this question.

\section{Other spe-9 class genes}

There are a number of other known mutations that cause worms to display a spe-9 class mutant phenotype (Table 1). These genes include spe-13, spe-36 and fer-14. The spe-13 gene is somewhat unique in the fact that although a fair number of mutant alleles have been identified, they are all temperature sensitive (E. Putiri and A. Singson, unpublished observations) (L'Hernault et al., 1988). Cloning of the fer-14 gene has not yet been published. However, it is predicted to encode a novel single-pass transmembrane molecule (T. Kroft and S. L'Hernault, personal communication). The molecular identification and subsequent analysis of these molecules will substantially increase our understanding of worm fertilization.

\section{The paternal effect lethal gene spe-11: a sperm gene re- quired for egg activation}

The spe-11 gene has a unique mutant phenotype. Sperm produced by spe-11 mutants enter oocytes. However these zygotes behave like unfertilized oocytes (Browning and Strome, 1996; Hill et al., 1989; L'Hernault et al., 1988; McNally and McNally, 2005; Roush, 1996). Oocytes fertilized by sperm produced by spe-11 mutants exhibit defects in meiosis, do not produce polar bodies, have defects in embryonic polarity, and do not secrete an eggshell (Hill et al., 1989; McNally and McNally, 2005). These mutant defects indicate that SPE-11 is not required for fertilization but rather is required for egg activation. It is striking that phenotypes that are similar to spe11 mutants can be generated by interfering with actin polymerization by Latrunculin A treatment or knockdown of the actin regulator profilin (Yang et al., 2003). As in other systems, there is a strong connection between the dynamics of the cytoskeleton and egg activation in $C$. elegans (Stitzel and Seydoux, 2007; Sun and Schatten, 2006).

The predicted protein encoded by the spe-11gene is a novel $36 \mathrm{kDA}$ cytoplasmic molecule that localizes to puncta associated with a sperm perinuclear halo (Browning and Strome, 1996). The significance of this localization in sperm is not clear. Particularly since the zygote does not necessarily need to obtain SPE-11 from sperm. Transgenic animals ectopically expressing SPE-11 in oocytes can be fertilized by sperm lacking SPE-11 to produce viable progeny (Browning and
Strome, 1996). An important future direction will not only be to discover how SPE-11 functions biochemically but also to determine if there are other sperm factors that are required for egg activation.

\section{Egg function genes}

The identification and characterization of egg function molecules is just as important as the identification of sperm molecules. Mutations that effect only egg function at fertilization or egg activation have been more difficult to isolate and maintain than their sperm counterparts. However, reverse genetic approaches (Kadandale et al., 2005; Maruyama et al., 2007) and promising genetic screening strategies for identifying conditional egg sterile mutants (E. Putiri, I. Chatterjee and A. Singson, unpublished) have made promising inroads with regards to this problem. The genes discussed here represent a promising start towards the study of this side of the fertilization equation in $C$. elegans (Fig. 2, Table 1).

\section{egg-1 and egg-2 encode partially redundant $L D L$ receptor repeat-containing transmembrane molecules}

Genome analysis and reverse genetics was used to identify the first candidate oocyte components of the fertilization machinery in C. elegans (Kadandale et al., 2005). Microarray data (Reinke et al., 2004) was examined for genes that display an oocyte-enriched expression pattern and encode transmembrane molecules with features or motifs known to be involved in ligand-receptor and cell-cell interactions. The first two genes to be studied in depth were egg-1 and egg-2 (Kadandale et al., 2005) (Table 1). These two genes encode type II transmembrane molecules with extracellular domains that contain arrays of eight low density lipoprotein (LDL)-receptor-repeats (Fig. 2).

The function of the egg-1 and egg-2 genes was assessed with a combination of RNAi and gene knockouts (Kadandale et al., 2005). Loss of function mutants or RNAi treated animals had no detectable somatic or gametogenesis defects. However, egg-1 and egg-2 are required semi-redundantly for hermaphrodite fertility. Loss of function of either egg-1 or egg-2 can lead to severely decreased hermaphrodite fertility. Loss of both genes leads to complete hermaphrodite sterility and wildtype sperm cannot enter the oocytes produced by these animals despite gamete contact. In contrast to this observation, male worms lacking egg-1 and egg-2 function have normal sperm production and fertility.

In order to investigate more fully the expression of EGG-1 and EGG-2 as well as determine their subcellular localization, transgenic worm strains carrying green fluorescent protein (GFP) fusions for these genes were created (Kadandale et al., 2005). When driven by their own promoters, EGG-1:GFP and EGG-2:GFP are restricted to the oocyte producing adult germline consistent with other reported expression data (Lee and Schedl, 2001; Reinke et al., 2004). Furthermore, the predicted topology and plasma membrane localization of EGG-1 was confirmed taking advantage of N-terminal and C-terminal GFP fusions and immunofluorescence. A simple model for EGG-1/ EGG-2 is that they function as oocyte surface receptors for sperm (Fig. 4). It will be critical to investigate the exact role of EGG-1 and EGG-2 in fertilization by identifying binding part- 
ners on the sperm surface (see below).

The egg-1 and egg-2 genes were likely the result of a gene duplication in the species lineage leading to $C$. elegans. There are single egg-1/egg-2 orthologues in the related nematode species C. briggsae and C. remanei (Kadandale et al., 2005), which are also required for fertility in these species. This gene duplication could give $C$. elegans a reproductive advantage and allow fecundity in a wider range of environmental conditions. In metazoa, LDL-receptor-related molecules are known to function as receptors for a wide variety of ligands and mediate a wide variety of cellular responses (Nykjaer and Willnow, 2002). In worms, LDL-receptor-related molecules are known to function in yolk uptake and fat metabolism (Ashrafi et al., 2003; Grant and Hirsh, 1999). It is intriguing to speculate that the egg-1/egg-2 genes evolved a role in sperm binding from ancestral genes involved in oocyte yolk uptake.

In addition to defects in fertilization, it was discovered that egg-1 mutants ovulated at levels that were considerably lower than wild-type controls (Kadandale et al., 2005). High levels of meiotic maturation and ovulation are known to require a sperm signal/sensing mechanism (Chatterjee et al., 2006; Govindan et al., 2006; Kosinski et al., 2005; McCarter et al., 1999). Mutants that are defective in this mechanism or lack sperm exhibit low meiotic maturation/ovulation level phenotypes similar to those seen in egg-1 mutants. In egg-1 mutants, at least part of the reduced ovulation levels is due to a loss of sperm (and thus loss of signal) from the reproductive tract. It was found that normal sperm had altered migratory behavior and that $e g g-1$ mutants were not maintaining a concentrated sperm population in the spermatheca. This discovery indicates the existence of previously unappreciated layers of regulation that help coordinate sperm migratory behavior and proper levels of meiotic maturation/ovulation with successful fertilization. Work with other fertility mutants has suggested that there are indeed differential effects on sperm loss and the coordination of fertili-

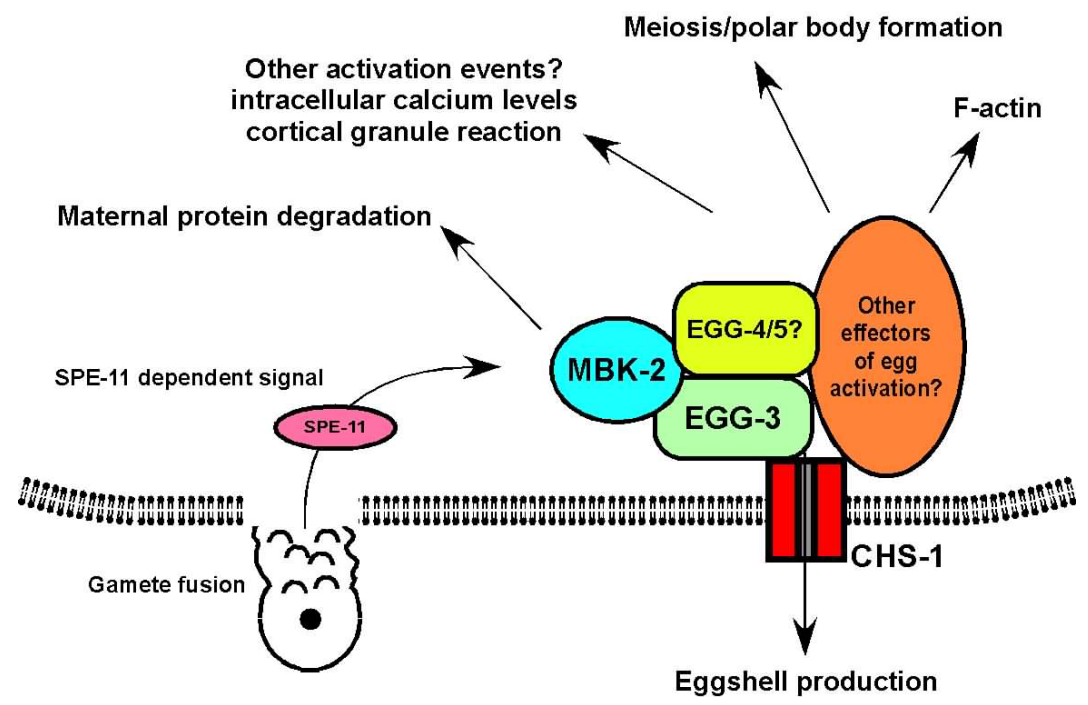

Fig. 5. A model for the EGG-3 complex and the regulation of key egg activation events. After sperm-egg fusion, egg activation is dependent of the activity of SPE-11. The EGG-3 complex then regulates eggshell formation, F-actin dynamics, the turnover of maternal proteins, meiosis/polar body formation, and other egg activation events. zation with meiotic maturation/ovulation rates in $C$. elegans (Kadandale and Singson, 2004; L'Hernault et al., 1988; McGovern et al., 2007).

\section{egg-3 encodes a protein tyrosine phosphatase-like (PTPL) family protein that is required for key aspects of egg activa- tion}

The egg-3 gene was initially identified as having a role in $C$. elegans fertility through a genome wide RNAi screen (Maeda et al., 2001). Gene knockout or RNAi of egg-3 resulted in sterile hermaphrodites while male fertility was unaffected (Maruyama et al., 2007). Gamete production, development and meiotic maturation were normal in egg-3 mutant hermaphrodites. Furthermore, egg-3 hermaphrodites were completely sterile and produced no progeny when crossed to wild-type males. Detailed phenotypic analysis revealed that wild-type sperm could enter oocytes produced by egg-3 mutants and that the block to polyspermy was intact. However, egg-3 mutant oocytes have defects in the polarized dispersal of F-actin after sperm entry. Additionally, egg3 mutant oocytes had other activation phenotypes that were strikingly similar to those that were described for spe-11 mutants (see above). This is an exciting result because it represents a rare gene pair (SPE-11 required in sperm and EGG-3 required in oocytes) that has the same mutant consequences on the zygote. Therefore EGG-3 is required for detecting a sperm entry signal(s) that includes or is dependent on SPE-11 function and triggers egg activation (Fig. 5).

The egg-3 gene encodes a member of the protein tyrosine phosphatase-like (PTPL) family (Maruyama et al., 2007; Stitzel et al., 2007). PTPL motifs lack key catalytic residues and are thought to encode inactive "anti-phosphatase" molecules. Anti-phosphatases are thought to function as competitors for active phosphatases or as scaffolds/adaptors with a role in regulating signaling or sequestering other molecules.

GFP fusions and antibody staining experiments revealed that EGG-3 is associated with the oocyte plasma membrane/cortex of developing oocytes. EGG-3 later disperses to cortical foci during meiotic anaphase I before being degraded (Maruyama et al., 2007; Stitzel et al., 2007). This dynamic localization pattern is not dependent on fertilization but is dependent on meiotic cell cycle progression. Furthermore, defects in meiosis are seen after anaphase I suggesting that the release of EGG-3 from its plasma membrane association must be important for its function. EGG-3 was found to colocalize with CHS1 and MBK-2. CHS-1 is a large channel protein required for eggshell synthesis and secretion (Johnston et al., 2006; Zhang et al., 2005) while MBK-2 encodes a DYRK kinase required to mark maternal proteins for degradation during early zygotic development (Pellettieri et al., 2003; Stitzel et al., 2006). The localization of EGG-3 and CHS-1 to the oocyte plasma membrane/cortex are interdependent. Both EGG-3 and CHS-1 are required for the proper localization of MBK-2. Biochemical analysis has shown that EGG-3 and MBK-2 can bind to each other (Stitzel et al., 2007). Binding and redistribution of EGG-3 and associated proteins in mei- 
otic anaphase is likely to regulate the timing of activity and/or access of molecules like MBK-2 to cytoplasmic targets (Govindan and Greenstein, 2007; Stitzel et al., 2007; Stitzel et al., 2006). Taken together, this data indicates that EGG-3 is in a position to influence the localization, access to substrates, and/or activity of molecular effectors of egg activation.

The mutant phenotype of egg-3, chs-1, and spe-11are similar. (Maruyama et al., 2007; McNally and McNally, 2005; Pellettieri et al., 2003; Stitzel et al., 2007; Stitzel et al., 2006). In contrast, mbk2 mutant defects are not as severe (Pang et al., 2004; Pellettieri et al., 2003). For instance, an eggshell is formed in mbk-2 mutants. Further, the localization of EGG-3 and CHS-1 are not dependent on MBK-2 (Maruyama et al., 2007; Stitzel et al., 2007). If MBK-2 were the only molecule regulated by EGG-3/CHS-1, then we would expect all of these genes to have identical mutant phenotypes. Therefore, EGG-3 is likely to regulate other effectors of egg activation.

We propose that EGG-3 and associated molecules form an oocyte membrane associated/cortex complex that is required for egg activation. A model for this complex that includes additional proteins suggested by recent experiments (R. Maruyama, R. Klancer, J. Parry and A. Singson, unpublished) and its outputs are shown in Figure 5. In this model, sperm entry is detected in a SPE11 dependent fashion by the EGG-3 complex. Various key aspects of egg activation are then regulated by the output of this complex. Finding additional components of this complex and its relationship to other aspects of egg activation such as calcium influx regulation are critical future directions. It will also be interesting to determine the relationship between SPE-11 and the EGG-3 complex.

\section{Future Directions}

\section{Identification of additional genes and determining their mo- lecular nature}

There must be many molecules that mediate the molecular underpinnings of the steps of fertilization in worms. It is improbable that the few molecules introduced in this review can mediate all the required steps. Therefore, at least with regards to our understanding of fertilization in C. elegans, we are still in the early gene discovery phase. There is a critical need to continue to screen for and isolate mutations that specifically affect sperm or egg function. Although a relatively groundbreaking approach in its application towards understanding fertilization, saturation screening is by no means a new idea in worms or other model systems (Jorgensen and Mango, 2002). Finally, not every gene required for fertilization will be gamete specific. The molecules that also have roles in somatic tissue will have to be discovered with novel genetic screening, genomic or biochemical based strategies.

\section{Making mechanistic connections between known molecules}

Making many mechanistic connections between the few currently known fertilization molecules is a bit of a long shot based on the many complex steps that must exist for successful fertilization in C. elegans. However, with an eye towards this goal, priority has been given to the study of some potential interactions.

EGG-1 and EGG-2 were attractive candidate receptors for SPE-9 (Fig. 4). Recent preliminary biochemical analysis suggest that the extracellular domains of SPE-9 and EGG-1 are not sufficient for binding to each other in vitro or when expressed on the surface of Drosophila cells in culture (B. Kong, A. StewartMichaelis, J. Bair, A. Xu and A. Singson, unpublished). This result suggests that the model in Figure 4B is correct and there are still important molecules on the surface of both sperm and oocytes that need to be identified.

With the localization patterns of several sperm molecules known (Fig. 3), it is possible to screen for mutant interacting genes that alter these patterns. SPE-38 and SPE-41/TRP-3 both localize to MOs in spermatids (Fig. 3) (Chatterjee et al., 2005; Xu and Sternberg, 2003). SPE-38 is not required for MO fusion with the plasma membrane or for the maintenance of plasma membrane domains (Chatterjee et al., 2005). However, it has recently been discovered that SPE-38 function is required for SPE-41/TRP-3 translocation to the plasma membrane (I. Chatterjee and $A$. Singson, unpublished). TRP family ion channels are ubiquitous and have diverse roles other than their roles in sperm motility and function (Jungnickel et al., 2001; Jungnickel et al., 2003; KahnKirby and Bargmann, 2006; Montell, 2004). The control of TRP channel subcellular localization and trafficking (particularly to the plasma membrane) is one of the most important yet least understood aspect of their regulation (Montell, 2004). A full investigation of this interaction could shed light on the regulation of TRP channel localization in other cellular contexts such as such as in neurite extension.

\section{Perspectives}

When reviewing progress in any model system, it is important to keep in mind how these studies can inform us with regards to work in other systems. All of the genes discussed in this review have homologues in other nematode species and several have been shown to have conserved functions (Geldziler et al., 2006; Kadandale et al., 2005; Maruyama et al., 2007). Reproductive proteins are known to diverge rapidly (Swanson and Vacquier, 2002; Vacquier, 1998). However, understanding the diversity of reproductive strategies can give us insights into the mechanisms of evolution and how nature deals with the universal issues of how cells interact with each other and their environment. In at least this way, continuing work in $C$. elegans will help us understand the common miracle of fertilization.

\section{Acknowledgements}

We would like to thank past and present members of the lab for providing unpublished results and many helpful discussions. We would also like to thank Tim Kroft and Steve L'Hernault for communicating unpublished data. J. S. H. is supported by a Busch Predoctoral Fellowship. J. M. P. is currently supported by an NSF GK-12 Teaching Fellowship. Research in the Singson Lab is currently supported by a grant from NIH (R56 HD054681).

\section{References}

ANDERSON, P. (1995). Mutagenesis. Methods in Cell Biology 48: 31-58.

ASHRAFI, K., CHANG, F. Y., WATTS, J. L., FRASER, A. G., KAMATH, R. S., AHRINGER, J., and RUVKUN, G. (2003). Genome-wide RNAi analysis of Caenorhabditis elegans fat regulatory genes. Nature 421: 268-272.

BARSTEAD, R. J. (1999). Reverse genetics, In C. elegans: a practical approach, I. A. Hope, ed. (Oxford, UK: Oxford University Press), pp. 97-118.

BEMBENEK, J. N., RICHIE, C. T., SQUIRRELL, J. M., CAMPBELL, J. M., ELICEIRI, 
K. W., POTERYAEV, D., SPANG, A., GOLDEN, A., and WHITE, J. G. (2007). Cortical granule exocytosis in $C$. elegans is regulated by cell cycle components including separase. Development 134: 3837-3848.

BOtTINO, D., MOGILNER, A., ROBERTS, T., STEWART, M., and OSTER,'G. (2002). How nematode sperm crawl. J Cell Sci115: 367-384.

BROWNING, H., and STROME, S. (1996). A sperm-supplied factor required for embryogenesis in C. elegans. Development 122: 391-404.

CASTELLANO, L. E., TREVINO, C. L., RODRIGUEZ, D., SERRANO, C. J., PACHECO, J., TSUTSUMI, V., FELIX, R., and DARSZON, A. (2003). Transient receptor potential (TRPC) channels in human sperm: expression, cellular localization and involvement in the regulation of flagellar motility. FEBS Lett 541: 69-74.

CHATTERJEE, I., KADANDALE, P., and SINGSON, A. (2006). Meiotic diapause: how a sperm signal sets you free. Curr Bio/16: R496-499.

CHATTERJEE, I., RICHMOND, A., PUTIRI, E., SHAKES, D. C., and-SINGSON, A. (2005). The-Caenorhabditis elegans spe-38 gene encodes a novel four-pass integral membrane protein required for sperm function at fertilization. Development 132: 2795-2808.

DAVIS, C. G. (1990). The many faces of epidermal growth factor repeats. New Biologist 2: 410-419.

DUCIBELLA, T., SCHULTZ, R. M., and OZIL, J. P. (2006). Role of calcium signals in early development. Semin Cell Dev Bio/17: 324-332.

EDGLEY, M. L., BAILLIE, D. L., RIDDLE, D. L., and ROSE, A. M. (1995). Genetic balancers. Methods in Cel/ Biology 48: 147-184.

FIRE, A. (1999). RNA-triggered gene silencing. Trends Genet 15:358-363.

FIRE, A., XU, S., MONTGOMERY, M. K., KOSTAS, S. A., DRIVER, S. E., and MELLO, C. C. (1998). Potent and specific genetic interference by doublestranded RNA inÄ Caenorhabditis elegans. Nature 391: 806-811.

FOOR, W. E. (1968). Zygote formation in Ascaris lumbricoides (Nematoda). J Cell Bio/39: 119-134.

GELDZILER, B., CHATTERJEE, I., KADANDALE, P., PUTIRI, E., PATEL, R., and SINGSON, A. (2006). A comparative study of sperm morphology, cytology and activation in Caenorhabditis elegans, Caenorhabditis remanei and Caenorhabditis briggsae. Dev Genes Evo/216: 198-208.

GELDZILER, B., CHATTERJEE, I., and SINGSON, A. (2005). The genetic and molecular analysis of spe-19: a gene required for sperm activation in Caenorhabditis elegans. Dev Bio/283: 424-436.

GELDZILER, B., KADANDALE, P., and SINGSON, A. (2004). Molecular genetic approaches to studying fertilization in model systems. Reproduction 127: 409416.

GOVINDAN, J. A., CHENG, H., HARRIS, J. E., and GREENSTEIN, D. (2006). Galphao/i and Galphas signaling function in parallel with the MSP/Eph receptor to control meiotic diapause in C. elegans. Curr Bio/16: 1257-1268.

GOVINDAN, J. A., and GREENSTEIN, D. (2007). Embryogenesis: anchors away! Curr Bio/17: R890-892.

GRANT, B., and HIRSH, D. (1999). Receptor-mediated endocytosis in the Caenorhabditis elegans oocyte. Mol Biol Cel/10: 4311-4326.

GREENSTEIN, D. (2005). Control of oocyte meiotic maturation and fertilization, In WormBook: online review of $C$. elegans biology, T. C. e. R. Community, ed. (http://www.wormbook.org).

GUNSALUS, K. C., GE, H., SCHETTER, A. J., GOLDBERG, D. S., HAN, J. D., HAO T., BERRIZ, G. F., BERTIN, N., HUANG, J., CHUANG, L. S., et al. (2005). Predictive models of molecular machines involved in Caenorhabditis elegans early embryogenesis. Nature 436: 861-865.

HARTGERS, F. C., VISSERS, J. L., LOOMAN, M. W., VAN ZOELEN, C., HUFFINE, C., FIGDOR, C. G., and ADEMA, G. J. (2000). DC-STAMP, a novel multimembrane-spanning molecule preferentially expressed by dendritic cells. Eur J Immuno/30: 3585-3590.

HILL, D. P., SHAKES, D. C., WARD, S., and STROME, S. (1989). A sperm-supplied product essential for initiation of normal embryogenesis in Caenorhabditis elegans is encoded by the paternal-effect embryonic-lethal gene, spe-11 [published erratum appears in Dev Bio/1990 May;139(1):230]. Dev Bio/136: 154-166.

HODGKIN, J. (1983). Male phenotypes and mating efficiency in Caenorhabditis elegans. Genetics 103: 43-64.
HODGKIN, J. (1997). Appendix 1: Genetics, In C. elegans II, D. L. Riddle, T. Blumenthal, B. J. Meyer, and J. R. Priess, eds. (Cold Spring Harbor: Cold Spring Harbor Laboratory Press), pp. 881-1048.

HODGKIN, J. (1999). Conventional genetics, In C. elegans: A Practical Approach, I. Hope, ed. (New York: Oxford University Press), pp. 245-270.

HODGKIN, J., PLASTERK, R. H. A., and WATERSTON, R. H. (1995). The nematode Caenorhabditis elegans and its genome. Science 270: 410-414.

HUBBARD, E. J., and GREENSTEIN, D. (2000). The Caenorhabditis elegans gonad: a test tube for cell and developmental biology. Dev Dyn 218: 2-22.

HUBBARD, E. J., and GREENSTEIN, D. (2005). Introduction to the germ line, In WormBook: online review of $C$. elegans biology, T. C. e. R. Community, ed. (http://www.wormbook.org).

JOHNSTON, W. L., KRIZUS, A., and DENNIS, J. W. (2006). The eggshell is required for meiotic fidelity, polar-body extrusion and polarization of the $C$. elegans embryo. BMC Bio/4: 35.

JONES, K. T. (2005). Mammalian egg activation: from Ca2+ spiking to cell cycle progression. Reproduction 130: 813-823.

JORGENSEN, E. M., and MANGO, S. E. (2002). The art and design of genetic screens: Caenorhabditis elegans. Nat Rev Genet 3: 356-369.

JUNGNICKEL, M. K., MARRERO, H., BIRNBAUMER, L., LEMOS, J. R., and FLORMAN, H. M. (2001). Trp2 regulates entry of $\mathrm{Ca} 2+$ into mouse sperm triggered by egg ZP3. Nat Cell Bio/3: 499-502.

JUNGNICKEL, M. K., SUTTON, K. A., and FLORMAN, H. M. (2003). In the beginning: lessons from fertilization in mice and worms. Cel/114: 401-404.

KADANDALE, P., and SINGSON, A. (2004). Oocyte production and sperm utilization patterns in semi-fertile strains of Caenorhabditis elegans. BMC Dev Bio/4: 3.

KADANDALE, P., STEWART-MICHAELIS, A., GORDON, S., RUBIN, J., KLANCER, R., SCHWEINSBERG, P., GRANT, B. D., and SINGSON, A. (2005). The Egg Surface LDL Receptor Repeat-Containing Proteins EGG-1 and EGG-2 Are Required for Fertilization in Caenorhabditis elegans. Curr Bio/15: 2222-2229.

KAHN-KIRBY, A. H., and BARGMANN, C. I. (2006). TRP channels in C. elegans. Annu Rev Physio/68: 719-736.

KOSINSKI, M., MCDONALD, K., SCHWARTZ, J., YAMAMOTO, I., and GREENSTEIN, D. (2005). C. elegans sperm bud vesicles to deliver a meiotic maturation signal to distant oocytes. Development 132: 3357-3369.

KROFT, T. L., GLEASON, E. J., and L'HERNAULT S, W. (2005). The spe-42gene is required for sperm-egg interactions during $C$. elegans fertilization and encodes a sperm-specific transmembrane protein. Dev Bio/286: 169-181.

KUBAGAWA, H. M., WATTS, J. L., CORRIGAN, C., EDMONDS, J. W., SZTUL, E., BROWSE, J., and MILLER, M. A. (2006). Oocyte signals derived from polyunsaturated fatty acids control sperm recruitment in vivo. Nat Cel/ Bio/8: 11431148.

KUKITA, T., WADA, N., KUKITA, A., KAKIMOTO, T., SANDRA, F., TOH, K., NAGATA, K., IIJIMA, T., HORIUCHI, M., MATSUSAKI, H., et al. (2004). RANKL-induced DC-STAMP is essential for osteoclastogenesis. J Exp Med 200: 941-946.

L'HERNAULT, S. W. (2006). Spermatogenesis, In WormBook: online review of $C$. elegans biology, T. C. e. R. Community, ed. (http://www.wormbook.org).

L'HERNAULT, S. W., SHAKES, D. C., and WARD, S. (1988). Developmental genetics of chromosome /spermatogenesis-defective mutants in the nematode Caenorhabditis elegans. Genetics 120: 435-452.

LAMITINA, T. (2006). Functional genomic approaches in C. elegans. Methods Mol Biol 351: 127-138.

LEE, M. H., and SCHEDL, T. (2001). Identification of in vivo mRNA targets of GLD1: a maxi-KH motif containing protein required for $C$. elegans germ cell development. Genes Dev 15: 2408-2420.

LESSARD, C., PENDOLA, J. K., HARTFORD, S. A., SCHIMENTI, J. C., HANDEL, M. A., and EPPIG, J. J. (2004). New mouse genetic models for human contraceptive development. Cytogenet Genome Res 105: 222-227.

LI, S., ARMSTRONG, C. M., BERTIN, N., GE, H., MILSTEIN, S., BOXEM, M., VIDALAIN, P. O., HAN, J. D., CHESNEAU, A., HAO, T., et al. (2004). A map of the interactome network of the metazoan C. elegans. Science 303: 540-543.

MAEDA, I., KOHARA, Y., YAMAMOTO, M., and SUGIMOTO, A. (2001). Largescale analysis of gene function in Caenorhabditis elegans by high-throughput 
RNAi. Curr Bio/11: 171-176.

MARUYAMA, R., and SINGSON, A. (2006). Taking care of Dad's DNA. Genome Bio/7: 244

MARUYAMA, R., VELARDE, N. V., KLANCER, R., GORDON, S., KADANDALE, P., PARRY, J. M., HANG, J. S., RUBIN, J., STEWART-MICHAELIS, A., SCHWEINSBERG, P., et al. (2007). EGG-3 Regulates Cell-Surface and Cortex Rearrangements during Egg Activation in Caenorhabditis elegans. Curr Bio/17: 1555-1560.

MCCARTER, J., BARTLETT, B., DANG, T., and SCHEDL, T. (1999). On the control of oocyte meiotic maturation and ovulation in C. elegans. Dev Bio/205: 111-128.

MCGOVERN, M., YU, L., KOSINSKI, M., GREENSTEIN, D., and SAVAGE-DUNN, C. (2007). A role for sperm in regulation of egg-laying in the nematode $C$. elegans. BMC Dev Bio/7: 41.

MCNALLY, K. L., and MCNALLY, F. J. (2005). Fertilization initiates the transition from anaphase I to metaphase II during female meiosis in C. elegans. Dev Biol 282: 218-230.

MILLER, M. A. (2006). Sperm and oocyte isolation methods for biochemical and proteomic analysis. Methods Mol Bio/351: 193-201.

MONTELL, C. (2004). Exciting trips for TRPs. Nat Cell Bio/6: 690-692.

NYKJAER, A., and WILLNOW, T. E. (2002). The low-density lipoprotein receptor gene family: a cellular Swiss army knife? Trends Cel/ Bio/12: 273-280.

PANG, K. M., ISHIDATE, T., NAKAMURA, K., SHIRAYAMA, M., TRZEPACZ, C., SCHUBERT, C. M., PRIESS, J. R., and MELLO, C. C. (2004). The minibrain kinase homolog, $m b k-2$ is required for spindle positioning and asymmetric cell division in early C. elegans embryos. Dev Bio/265: 127-139.

PELLETTIERI, J., REINKE, V., KIM, S. K., and SEYDOUX, G. (2003). Coordinate activation of maternal protein degradation during the egg-to-embryo transition in C. elegans. Dev Cel/5: 451-462.

PIANO, F., GUNSALUS, K. C., HILL, D. E., and VIDAL, M. (2006). C. elegans network biology: a beginning, In WormBook: online review of $C$. elegans biology, T. C. e. R. Community, ed. (http://www.wormbook.org).

PUTIRI, E., ZANNONI, S., KADANDALE, P., and SINGSON, A. (2004). Functional domains and temperature-sensitive mutations in SPE-9: an EGF repeat-containing protein required for fertility in Caenorhabditis elegans. Dev Bio/272: 448459.

REINKE, V., GIL, I. S., WARD, S., and KAZMER, K. (2004). Genome-wide germline-enriched and sex-biased expression profiles in Caenorhabditis elegans. Development 131: 311-323.

REINKE, V., SMITH, H. E., NANCE, J., WANG, J., VAN DOREN, C., BEGLEY, R., JONES, S. J., DAVIS, E. B., SCHERER, S., WARD, S., and KIM, S. K. (2000). A global profile of germline gene expression in C. elegans. Mo/ Cel/6: 605-616.

ROBERTS, T. M., PAVALKO, F. M., and WARD, S. (1986). Membrane and cytoplasmic proteins are transported in the same organell complex during nematode spermatogenesis. Journal of Cell Biology 102: 1787-1796.

ROUSH, W. (1996). Sperm protein makes its mark upon the worm embryo. Science 271: 33.

ROY, A., and MATZUK, M. M. (2006). Deconstructing mammalian reproduction: using knockouts to define fertility pathways. Reproduction 131: 207-219.

SAMUEL, A. D., MURTHY, V. N., and HENGARTNER, M. O. (2001). Calcium dynamics during fertilization in C. elegans. BMC Dev Bio/1: 8 .

SCHNABEL, R., and PRIESS, J. R. (1997). Specification of Cell Fates in the Early Embryo, In C. Elegans II, T. Blumenthal, B. J. Meyer, and J. R. Priess, eds. (Cold Spring Harbor: Cold Spring Harbor Laboratory), pp. 361-382.

SHAKES, D., and WARD, S. (1989a). Mutations That Disrupt the Morphogenesis and Localization of a Sperm-Specific Organelle in Caenorhabditis elegans. Developmental Biology 134: 307-316.
SHAKES, D. C., and WARD, S. (1989b). Initiation of spermiogenesis in C. elegans. a pharmacological and genetic analysis. Dev Bio/134: 189-200.

SINGSON, A. (2001). Every sperm is sacred: fertilization in Caenorhabditis elegans. Dev Bio/230: 101-109.

SINGSON, A. (2006). Sperm activation: time and tide wait for no sperm. Curr Biol 16: R160-162.

SINGSON, A., MERCER, K. B., and L'HERNAULT, S. W. (1998). The C. elegans spe-9 gene encodes a sperm transmembrane protein that contains EGF-like repeats and is required for fertilization. Cel/93: 71-79.

STITZEL, M. L., CHENG, K. C., and SEYDOUX, G. (2007). Regulation of MBK-2/ Dyrk Kinase by Dynamic Cortical Anchoring during the Oocyte-to-Zygote Transition. Curr Bio/17: 1545-1554.

STITZEL, M. L., PELLETTIERI, J., and SEYDOUX, G. (2006). The C. elegans DYRK Kinase MBK-2 Marks Oocyte Proteins for Degradation in Response to Meiotic Maturation. Curr Bio/ 16: 56-62.

STITZEL, M. L., and SEYDOUX, G. (2007). Regulation of the oocyte-to-zygote transition. Science 316: 407-408.

SUN, Q. Y., and SCHATTEN, H. (2006). Regulation of dynamic events by microfilaments during oocyte maturation and fertilization. Reproduction 131: 193-205.

SWANSON, W. J., and VACQUIER, V. D. (2002). The Rapid Evolution of Reproductive Proteins. Nature Reviews Genetics 3: 137-144.

THERIOT, J. A. (1996). Worm sperm and advances in cell locomotion. Cel/84: 1-

TSAADON, A., ELIYAHU, E., SHTRAIZENT, N., and SHALGI, R. (2006). When a sperm meets an egg: block to polyspermy. Mol Cel/ Endocrino/252: 107-114.

VACQUIER, V. D. (1998). Evolution of gamete recognition proteins. Science 281: 1995-1998.

WAKIMOTO, B. T., LINDSLEY, D. L., and HERRERA, C. (2004). Toward a comprehensive genetic analysis of male fertility in Drosophila melanogaster. Genetics 167: 207-216.

WARD, S., ARGON, Y., and NELSON, G. A. (1981). Sperm morphogenesis in wildtype and fertilization-defective mutants of Caenorhabditis elegans. J Cell Biol 91: 26-44.

WARD, S., and CARREL, J. S. (1979). Fertilization and sperm competition in the nematode Caenorhabditis elegans. Dev Bio/73: 304-321.

WARD, S., HOGAN, E., and NELSON, G. A. (1983). The initiation of spermiogenesis in the nematode Caenorhabditis elegans. Dev Bio/98: 70-79.

WILSON, K. L., FITCH, K. R., BAFUS, B. T., and WAKIMOTO, B. T. (2006). Sperm plasma membrane breakdown during Drosophila fertilization requires sneaky, an acrosomal membrane protein. Development 133: 4871-4879.

XU, X. Z., and STERNBERG, P. W. (2003). A C. elegans sperm TRP protein required for sperm-egg interactions during fertilization. Cel/114: 285-297.

YAMAMOTO, I., KOSINSKI, M. E., and GREENSTEIN, D. (2006). Start me up: cell signaling and the journey from oocyte to embryo in C. elegans. Dev Dyn 235: 571-585.

YANG, H. Y., MCNALLY, K., and MCNALLY, F. J. (2003). MEI-1/katanin is required for translocation of the meiosis I spindle to the oocyte cortex in $C$ elegans. Dev Bio/260: 245-259

ZANNONI, S., L'HERNAULT, S. W., and SINGSON, A. W. (2003). Dynamic localization of SPE-9 in sperm: a protein required for sperm-oocyte interactions in Caenorhabditis elegans. BMC Dev Bio/3: 10.

ZHANG, Y., FOSTER, J. M., NELSON, L. S., MA, D., and CARLOW, C. K. (2005). The chitin synthase genes $c h s-1$ and $c h s-2$ are essential for $C$. elegans development and responsible for chitin deposition in the eggshell and pharynx, respectively. Dev Bio/285: 330-339. 


\section{Related, previously published Int. J. Dev. Biol. articles}

See our recent Special Issue Ear Development edited by Fernando Giraldez and Bernd Fritzsch at: http://www.ijdb.ehu.es/web/contents.php?vol=51\&issue=6-7

The role of ion fluxes in polarized cell growth and morphogenesis: the pollen tube as an experimental paradigm Erwan Michard, Filipa Alves and José A. Feijó

Int. J. Dev. Biol. (2008) 52: doi: 10.1387/ijdb.072296em

Basic Science B.D. (before Drosophila): Cytology at Warsaw University (Poland)

Malgorzata Kloc

Int. J. Dev. Biol. (2008) 52: 115-119

Egg development in parthenogenetic nematodes: variations in meiosis and axis formation Vera Lahl, Bernd Sadler and Einhard Schierenberg

Int. J. Dev. Biol. (2006) 50: 393-397

Expression of ADP-ribosylation factor (ARF)-like protein 6 during mouse embryonic development Tatsuyuki Takada, Keiko lida, Hiroshi Sasaki, Masanori Taira and Hiroshi Kimura Int. J. Dev. Biol. (2005) 49: 891-894

Differences in maternal supply and early development of closely related nematode species Magdalena Laugsch and Einhard Schierenberg Int. J. Dev. Biol. (2004) 48: 655-662

Genetic control of gamete quality in the mouse - a tribute to Halina Krzanowska Jozefa Styrna

Int. J. Dev. Biol. (2008) 52: 195-199

Cadherin- 6 is required for zebrafish nephrogenesis during early development Fumitaka Kubota, Tohru Murakami, Kenji Mogi and Hiroshi Yorifuji Int. J. Dev. Biol. (2007) 51: 123-129

TBX1, a DiGeorge syndrome candidate gene, is inhibited by retinoic acid Lifeng Zhang, Tao Zhong, Yuexiang Wang, Qu Jiang, Houyan Song and Yonghao Gui Int. J. Dev. Biol. (2006) 50: 55-61

2006 ISI ${ }^{* *}$ Impact Factor $=3.577^{* *}$

A generalized caspase inhibitor disrupts early mammalian development Zahra Zakeri Richard A. Lockshin, Luis-Miguel Criado-Rodríguez and Carlos Martínez-A

Int. J. Dev. Biol. (2005) 49: 43-51

$\mathrm{Ca2+-independent} \mathrm{protein} \mathrm{kinase} \mathrm{C}$ signalling in mouse eggs during the early phases of fertilization.

Carla Tatone, Simona Delle Monache, Antonella Francione, Luisa Gioia, Barbara Barboni and Rosella Colonna

Int. J. Dev. Biol. (2003) 47: 327-333

Fertilization triggers activation of Fyn kinase in the zebrafish egg. W Wu and W H Kinsey

Int. J. Dev. Biol. (2000) 44: 837-841

The role of stem cell factor and of alternative c-kit gene products in the establishment, maintenance and function of germ cells.

C Sette, S Dolci, R Geremia and P Rossi

Int. J. Dev. Biol. (2000) 44: 599-608

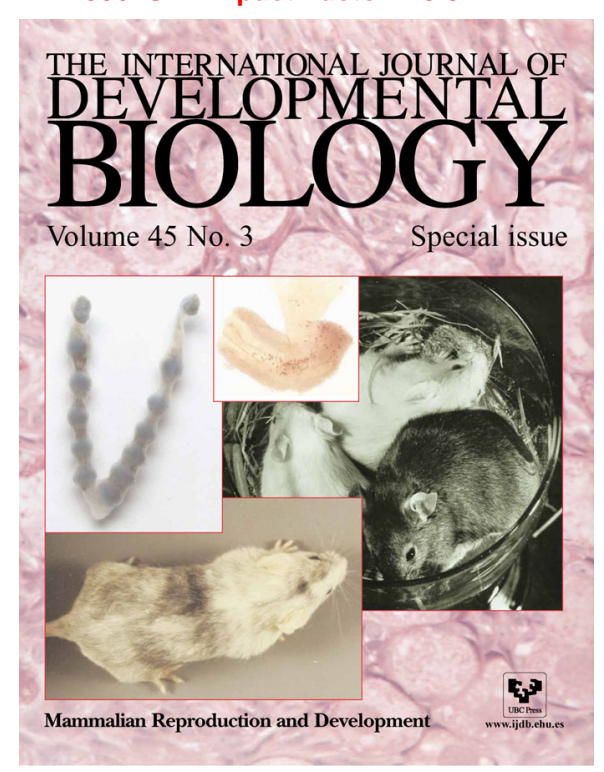

